\title{
Investigations of the superlubricity of sapphire against ruby under phosphoric acid lubrication
}

\author{
Jinjin LI ${ }^{1}$, Chenhui ZHANG ${ }^{1,2}$, Mingming DENG ${ }^{1}$, Jianbin LUO ${ }^{1, *}$ \\ ${ }^{1}$ State Key Laboratory of Tribology, Tsinghua University, Beijing, 100084, China \\ ${ }^{2}$ Shenzhen Key Laboratory of Micro-Nano Manufacturing, Research Institute of Tsinghua University in Shenzhen, Shenzhen, 518057, China \\ Received: 11 March 2014 / Revised: 03 April 2014 / Accepted: 22 April 2014 \\ (C) The author(s) 2014. This article is published with open access at Springerlink.com
}

\begin{abstract}
In this study, we address the superlubricity behavior of sapphire against ruby (or sapphire against itself) under phosphoric acid solution lubrication. An ultra-low friction coefficient of 0.004 was obtained under a very high contact pressure, with a virgin contact pressure up to $2.57 \mathrm{GPa}$. Related experiments have indicated that the load, sliding speed, and humidity of the test environment can affect superlubricity to some degree, so we tested variations in these conditions. When superlubricity appears in this study a thin film is present, consisting of a hydrogen bond network of phosphoric acid and water molecules adsorbed on the two friction surfaces, which accounts for the ultra-low friction. Most significantly, the wear rate of the sapphire and ruby in the friction process is very slow and the superlubricity state is very stable, providing favorable conditions for future technological applications.
\end{abstract}

Keywords: friction; superlubricity; sapphire; aqueous lubrication

\section{Introduction}

Since the 1990s when the term superlubricity was coined [1], it has been used to describe the physical phenomenon that the friction force between two surfaces is very small. Usually, when the ratio of friction force to load in a sliding system is less than 0.01, it is referred to as being in a state of superlubricity [2]. Superlubricity is beneficial for saving energy and reducing wear in mechanical systems, so it has attracted a great amount of attention among tribology researchers [3-7]. At present, there are two main methods for obtaining superlubricity. The first is to change the properties of the friction surfaces so they have incommensurate contact or interfacial interaction (solid superlubricity). This method is used in manufacturing diamond-like carbon (DLC) film [8], $\mathrm{MoS}_{2}$ film [9], and $\mathrm{CN}_{x}$ film [10]. The second method is to add a lubricant between the two friction surfaces to

* Corresponding author: Jianbin LUO.

E-mail: luojb@tsinghua.edu.cn separate them (liquid superlubricity). However, the most common lubricants, various kinds of oil, cannot realize superlubricity due to their high pressureviscosity coefficients. Water lubricants have greater potential for achieving superlubricity because of their low pressure-viscosity coefficients [11]. Klein et al. obtained superlubricity between two mica surfaces lubricated by a surfactant layer and charged polymers at a nano-scale using a surface force apparatus (SFA) [12-14]. Kato et al. obtained superlubricity between two ceramic surfaces $\left(\mathrm{Si}_{3} \mathrm{~N}_{4} / \mathrm{CN}_{x} / \mathrm{SiC}\right)$ with water lubrication at a macro-scale using a traditional tribometer $[15,16]$. Superlubricity has also been achieved using lubricants such as glycerol (between two DLC surfaces) [17, 18], a polymer brush (between two $\mathrm{SiO}_{2}$ surfaces) [19], and plant mucilage (between two glass surfaces) [20]. In our previous work, we also obtained superlubricity between ceramic $\left(\mathrm{Si}_{3} \mathrm{~N}_{4}\right)$ and glass surfaces lubricated by a phosphoric acid solution and mixtures of polyhydroxy alcohol and acid solutions [21-23].

However, the contact pressures for the liquid superlubricities mentioned above are not very high (less 
than $1 \mathrm{GPa}$ ). There is a question as to whether or not superlubricity can be achieved under much higher contact pressure. Obviously, high pressure has many disadvantages for liquid superlubricity, such as the potential for significant deformation, severe wear, and the lubricant molecules being squeezed out. These challenges have made it very difficult to achieve superlubricity under high pressure. If these three disadvantages can be solved, then the liquid superlubricity under high pressure becomes possible.

Recently, we found that the liquid superlubricity can be achieved even when the initial maximal contact pressure between two friction surfaces reaches up to 2.57 GPa, when using sapphire and ruby (or sapphire against its own) surfaces lubricated by a phosphoric acid solution $(\mathrm{pH}=1.5)$. This superlubricity state is very stable, and can last for more than $9 \mathrm{~h}$. Therefore, in this paper we investigate the superlubricity behavior and mechanism when using these surfaces and this lubricant, and discuss the relationship between the lubrication conditions (load, speed, and humidity) and superlubricity.

\section{Experimental section}

The friction pairs are a ruby or sapphire ball with a diameter of $5 \mathrm{~mm}$ and a sapphire plate with a diameter of $20 \mathrm{~mm}$ and a thickness of $3 \mathrm{~mm}$ (both obtained from Zhaohong Technology Co. Ltd., China). The surface roughness $\left(R_{z}\right)$ of the ball and plate is about $12 \mathrm{~nm}$. Both the ball and the plate were cleaned in an ultrasonic bath with acetone and ethanol for 15 min sequentially, and then washed with deionized water and dried with compressed air prior to the test. The lubricant, a phosphoric acid $\left(\mathrm{H}_{3} \mathrm{PO}_{4}\right)$ solution with a $\mathrm{pH}$ value of 1.5 (corresponding to a concentration of $1.6 \%(\mathrm{w} / \mathrm{w})$ ), was prepared by diluting commercial phosphoric acid (obtained from Beijing Chemical Works, purity > $99 \%$ and concentration $>85 \%$ ) with deionized water. Before the friction test, a few droplets of this lubricant $(10 \mu \mathrm{L})$ were dripped between the ball and the plate.

The friction coefficient was measured on a Universal Micro-Tribotester (UMT-3, Bruker) using a ball-on-disk model. The load applied on the disk ranged from $0.5 \mathrm{~N}$ to $15 \mathrm{~N}$. According to the Hertz contact theory and with regard to the mechanical properties of friction surfaces (elasticity modulus $=425 \mathrm{GPa}$, Poisson's ratio = 0.30 ), the maximal contact pressure is between $0.95 \mathrm{GPa}$ and $2.94 \mathrm{GPa}$. The rotation speed of the disk ranged from $5 \mathrm{rpm}$ to 1,200 rpm, and the radius of the sliding track on the disk was $3 \mathrm{~mm}$, corresponding to a linear sliding speed of $0.00157 \mathrm{~m} / \mathrm{s}$ to $0.377 \mathrm{~m} / \mathrm{s}$. The ambient temperature was about $25{ }^{\circ} \mathrm{C}$ and the relative humidity of the test environment ranged from $10 \%$ to $100 \%$. To obtain an accurate friction coefficient value, measuring errors were eliminated by adjusting the disk levelness until the same friction coefficients were obtained in reverse sliding directions (for more details see Ref. [19]) [24].

The topography of the friction surfaces was investigated with a white light interferometer (MICROXAM3D) and an optical microscope (Olympus). The details of the wear region were investigated with an atomic force microscope (AFM, Nanoman VS). The images were obtained under ambient conditions in tapping mode. The chemical composition of the worn surfaces was measured with a confocal Raman spectrometer (Jobin Yvon HR800). The laser, with a wavelength of $514 \mathrm{~nm}$, was focused on the sample through a 50× objective microscope.

\section{Results and discussions}

Figure 1 shows the evolution of the friction coefficient over time for sapphire against ruby lubricated with an $\mathrm{H}_{3} \mathrm{PO}_{4}$ solution $(\mathrm{pH}=1.5)$. The friction coefficient is 0.2 at the beginning of test. After about $320 \mathrm{~s}$, the friction coefficient reduced to a value of 0.004 , entering the superlubricity regime. Here, the time elapsed from the beginning of the test to the appearance of the lowest friction value is defined as the running-in period. After this $320 \mathrm{~s}$ running-in period, the friction coefficient maintains this ultra-low value $(\mu=0.004)$ until the end of the test $(2,000 \mathrm{~s})$. The friction coefficient was measured more than ten times, and all the friction curves over time (decreasing during the running-in period and then approaching a steady-state value) are almost identical in every test. We then changed the ruby ball to a sapphire ball, and found that superlubricity can also be obtained using sapphire against sapphire; the resulting friction curve is the same as that for sapphire against ruby. This indicates 


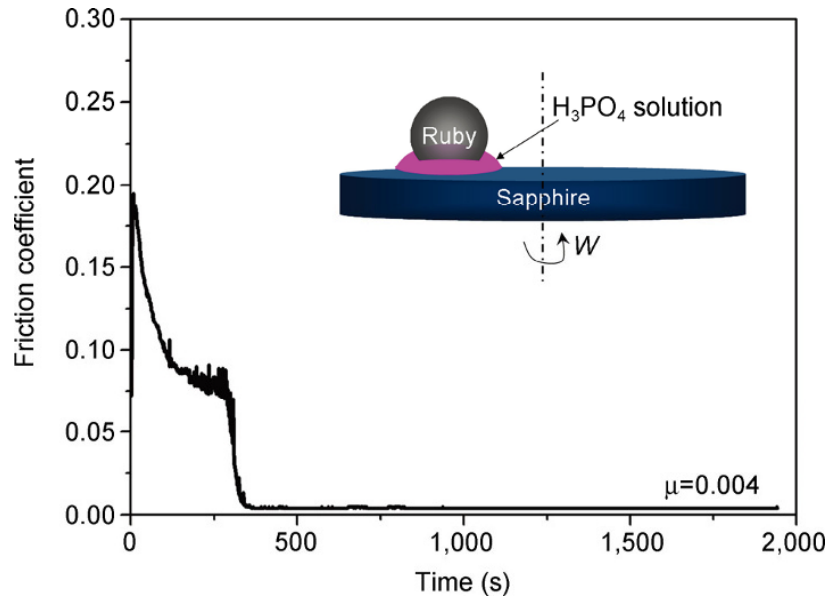

Fig. 1 Friction coefficient over time with the $\mathrm{H}_{3} \mathrm{PO}_{4}$ solution lubricant $(\mathrm{pH}=1.5)$, with a load of $3 \mathrm{~N}$, a rotation speed of 180 rpm, and humidity at $30 \%$.

that the superlubricity is independent of the chromium $(\mathrm{Cr})$ in the ruby. In addition, we found that the ultralow friction state $(\mu=0.004)$ can last for more than $9 \mathrm{~h}$, indicating the stability of this superlubricity state.

Next, we studied the effect of speed and applied load on superlubricity, as shown in Figs. 2(a) and 2(b). We found that superlubricity $(\mu<0.01)$ can be obtained when the rotation speed is greater than $15 \mathrm{rpm}$ (sliding speed $=0.00471 \mathrm{~m} / \mathrm{s}$ ). In addition, when the rotation speed is greater than $30 \mathrm{rpm}$ (sliding speed = $0.00942 \mathrm{~m} / \mathrm{s})$, the friction coefficient remains nearly constant $(\mu=0.004)$. However, when the rotation speed decreases from $30 \mathrm{rpm}$ to $5 \mathrm{rpm}$, the friction coefficient increases from 0.004 to 0.017 . And when the rotation speed reduces to $5 \mathrm{rpm}$ (sliding speed $=0.00157 \mathrm{~m} / \mathrm{s}$ ), superlubricity $(\mu<0.01)$ can no longer be achieved. With respect to load, we found that the friction coefficient remains nearly constant $(\mu=0.004)$ when the load ranges from $0.5 \mathrm{~N}$ to $10 \mathrm{~N}$, but increases when the applied load increases from $10 \mathrm{~N}$ to $15 \mathrm{~N}$. When the applied load reaches $15 \mathrm{~N}$, superlubricity $(\mu<0.01)$ can no longer be obtained. From these results, we conclude that when the sliding speed is greater than $0.00942 \mathrm{~m} / \mathrm{s}$ and the applied load is less than $10 \mathrm{~N}$, changes in speed and load have almost no effect on superlubricity.

To investigate the superlubricity behavior of sapphire against ruby, as observed above, we carried out a series of experiments as follows. At the beginning of test, the $\mathrm{H}_{3} \mathrm{PO}_{4}$ solution was in a fluid state and was
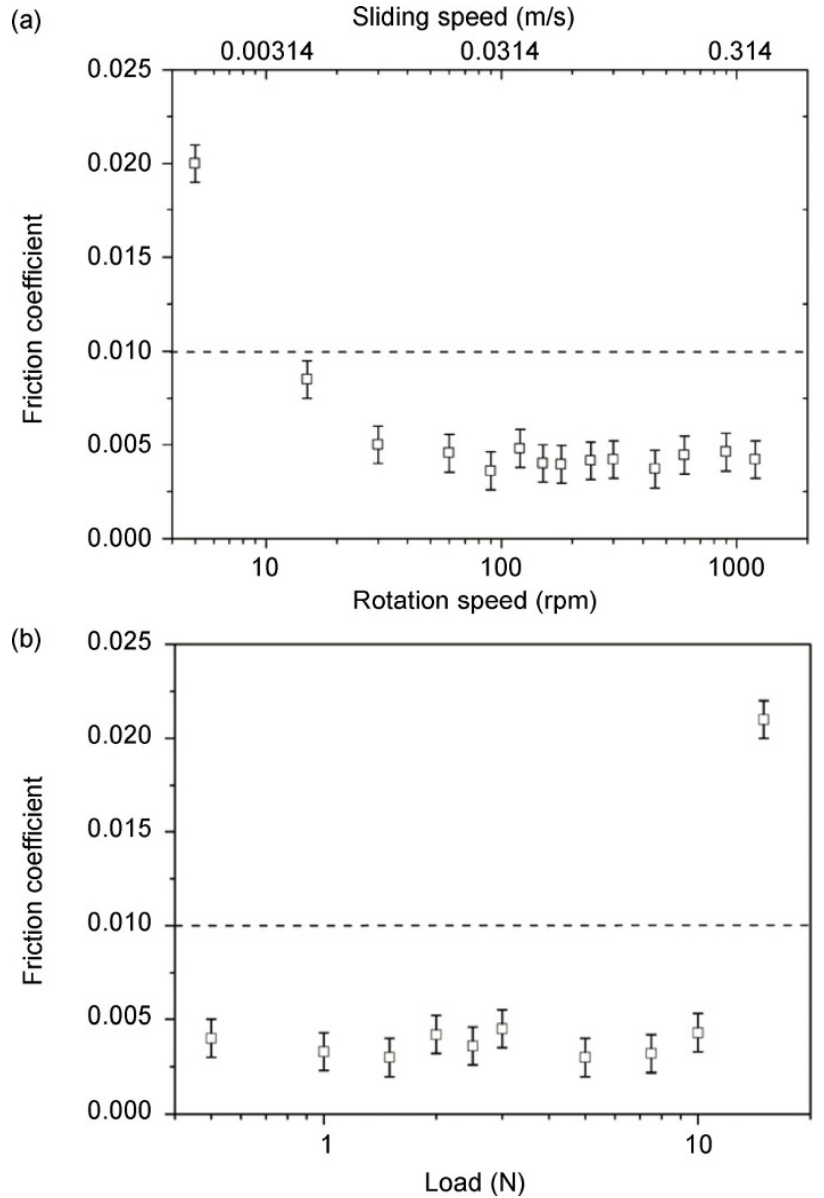

Fig. 2 (a) Lowest friction coefficient when using $\mathrm{H}_{3} \mathrm{PO}_{4}$ solution lubrication $(\mathrm{pH}=1.5)$ with different rotation speeds, a load of 3 $\mathrm{N}$, and humidity at $30 \%$. (b) Lowest friction coefficient when using $\mathrm{H}_{3} \mathrm{PO}_{4}$ solution lubrication $(\mathrm{pH}=1.5)$ with different loads, a rotation speed of $180 \mathrm{rpm}$, and humidity at $30 \%$.

confined between the two friction surfaces. During the running-in period, the free water in the solution was evaporated gradually. When superlubricity appeared, there was almost no fluid remaining on the sapphire plate, and a transparent solid-like film had formed on the plate instead. To observe this film in greater detail, we used the optical microscope to study both the plate and the ball, as shown in Figs. 3(a) and 3(b). We found the thin film to be adsorbed both on the track of the plate and on the top region of the ball. To analyze this thin film's chemical composition, we measured its Raman spectrum, as shown in Figs. 3(c) and 3(d). We observed that the thin film adsorbed on the track had a strong scattering peak at $910 \mathrm{~cm}^{-1}$ (with other peaks at $378 \mathrm{~cm}^{-1}, 417 \mathrm{~cm}^{-1}$, and $643 \mathrm{~cm}^{-1}$ that are typical of sapphire bonds), indicating the bond of 

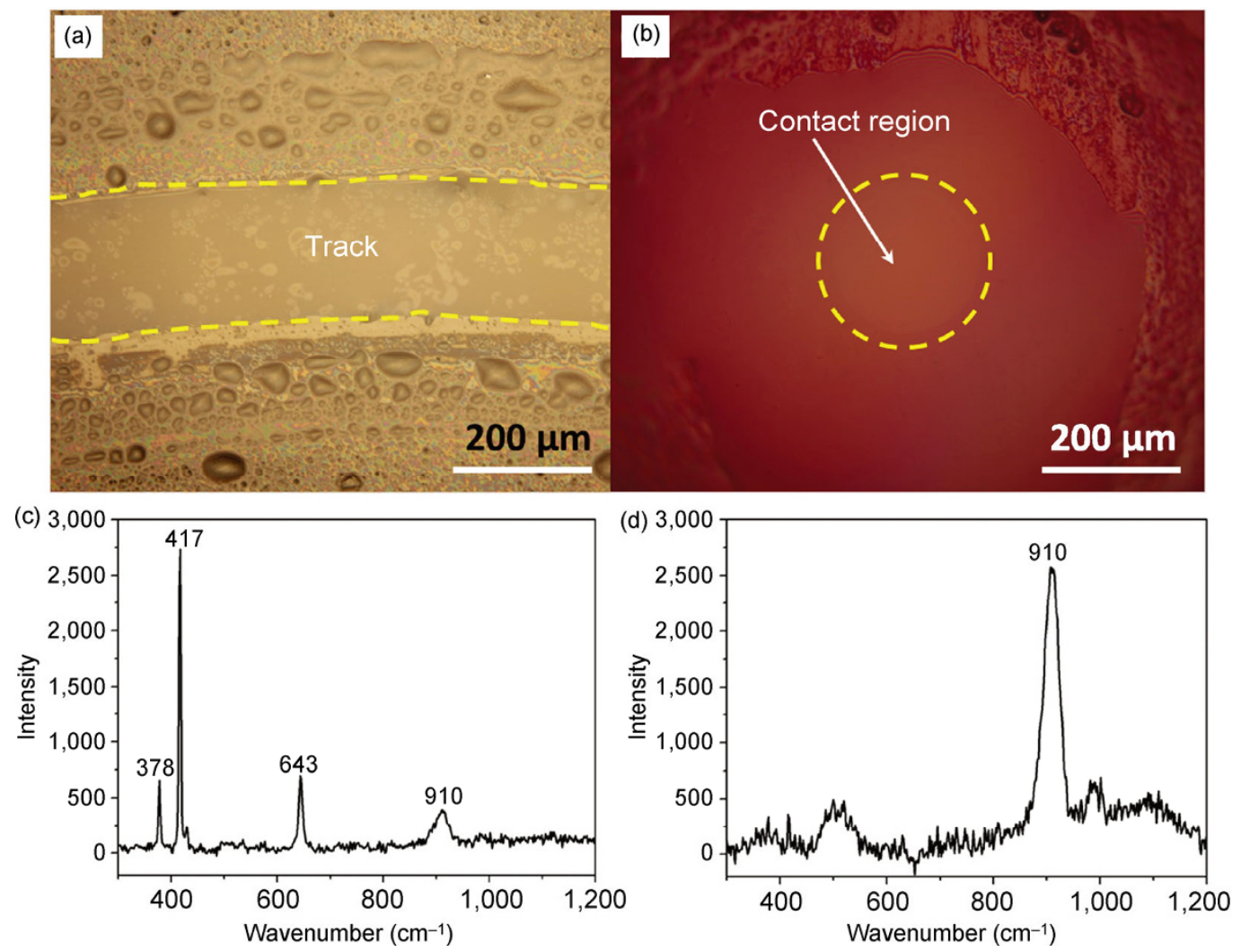

Fig. 3 (a) Optical image of the track on the sapphire plate after the friction test. (b) Optical image of the top region on the ruby ball after the friction test. (c) Raman spectrum of the thin film adsorbed on the track after the friction test. (d) Raman spectrum of the thin film adsorbed on the top region of the ball after the friction test.

the $\mathrm{P}-\mathrm{OH}$ symmetric stretch of the $\mathrm{H}_{3} \mathrm{PO}_{4}$ molecule and the $\mathrm{H}_{2} \mathrm{PO}_{4}^{-}$ions (by ionization) [25]. A shift to a higher frequency has been observed relative to the typical bond of a P-OH symmetric stretch $\left(890 \mathrm{~cm}^{-1}\right)$ in dilute $\mathrm{H}_{3} \mathrm{PO}_{4}$ solution [26], which indicates that a strong hydrogen bond effect exists in the film adsorbed on the track [27]. Therefore, we concluded that a hydrogen bond network composed of $\mathrm{H}_{3} \mathrm{PO}_{4}, \mathrm{H}_{2} \mathrm{PO}_{4}^{-}$, and $\mathrm{H}_{2} \mathrm{O}$ had formed in the thin film. We also found that the Raman spectrum of the thin film adsorbed on the top region of the ball $\left(910 \mathrm{~cm}^{-1}\right)$ was almost identical to that on the track, indicating the presence of the same thin film with a hydrogen bond network adsorbed on the top region of the ball.

To further investigate the topography of the friction surfaces, we measured both the track on the plate and the top region of the ball using a white light interferometer after washing the adsorbed film with de-ionized water for about $10 \mathrm{~min}$, as shown in Figs. 4(a) and $4(b)$. We can see a concave track with a width of
$160 \mu \mathrm{m}$ and a depth of $15 \mathrm{~nm}$ on the plate. The depth is so shallow that the track is difficult to identify with the optical microscope. On the top region of the ball, there is a worn flat region with a diameter of $200 \mu \mathrm{m}$. From these two images, we determined the wear volume of the sapphire and the ruby to be about $4.52 \times$ $10^{-5} \mathrm{~mm}^{3}$ and $3.14 \times 10^{-4} \mathrm{~mm}^{3}$, respectively, with a corresponding wear rate of $2.67 \times 10^{-10} \mathrm{~mm}^{3} / \mathrm{Nm}$ and $1.85 \times 10^{-9} \mathrm{~mm}^{3} / \mathrm{Nm}$, respectively. These results indicate that the wear rates of sapphire and ruby is much lower than the wear rates of ceramics $\left(10^{-8}-10^{-6} \mathrm{~mm}^{3} / \mathrm{Nm}\right)$ with water lubrication [28].

To study the friction surfaces in greater detail, both the track on the plate and the worn region of the ball were observed under an AFM, as shown in Figs. 5(b) and 5(c). We found many shallow micro-grooves along the sliding direction on the track surface. From Fig. 5(e), it can be seen that the width of the grooves is several micrometers and the depth is several nanometers. Compared with the original surface of the 

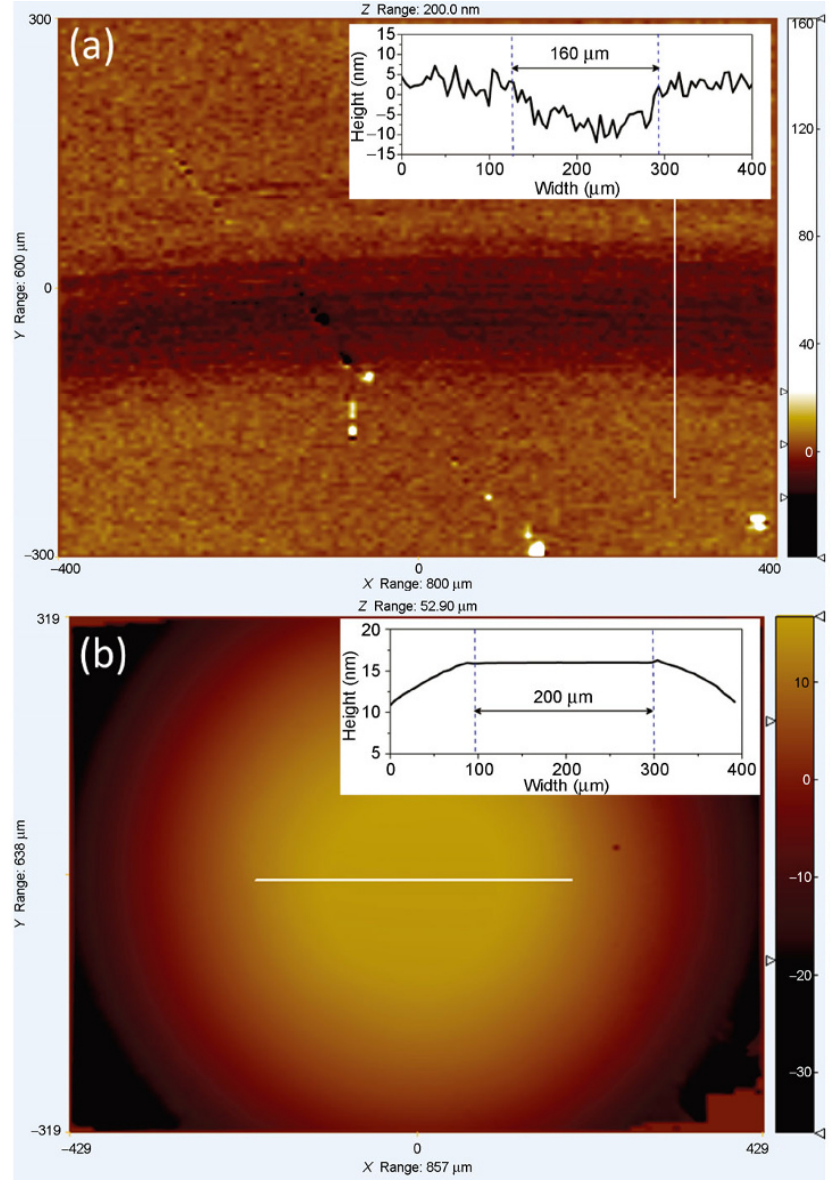

Fig. 4 (a) Topography of the track on the plate. (b) Topography of the top region of the ball. sapphire (Fig. 5(a)), the surface roughness $\left(R_{z}\right)$ increases from $0.486 \mathrm{~nm}$ to $5.506 \mathrm{~nm}$, indicating that the rubbing surface becomes much rougher when superlubricity appears. On the worn region of the ball, there are also some shallow micro-grooves along the sliding direction. In addition, there are many nano-particles of different sizes adsorbed onto the worn region of the ball, which are the abrasive particles from the worn surfaces. From these results, we infer that the micro-grooves on the rubbing surfaces are produced by the plowing effect of these nano-particles between the two surfaces during the running-in process.

As mentioned above, there is a thin film with a hydrogen bond network of $\mathrm{H}_{3} \mathrm{PO}_{4}, \mathrm{H}_{2} \mathrm{PO}_{4}^{-}$, and $\mathrm{H}_{2} \mathrm{O}$ molecules between the two friction surfaces when superlubricity appears. It can be inferred that if excess free water is introduced in the contact region, it would destroy the hydrogen bond network by breaking the equilibrium state between the $\mathrm{H}_{3} \mathrm{PO}_{4}$ and $\mathrm{H}_{2} \mathrm{O}$ molecules, which would then lead to high friction. To confirm this inference, different volumes of deionized water $(1 \mu \mathrm{L}, 3 \mu \mathrm{L}$, and $5 \mu \mathrm{L})$ were added to the track when the friction coefficient reached its lowest value, as shown in Fig. 6. We found that the friction coefficient becomes suddenly high (from 0.004 to 0.07 ) once deionized water is introduced. However, superlubricity can be restored after a short running-in period. In
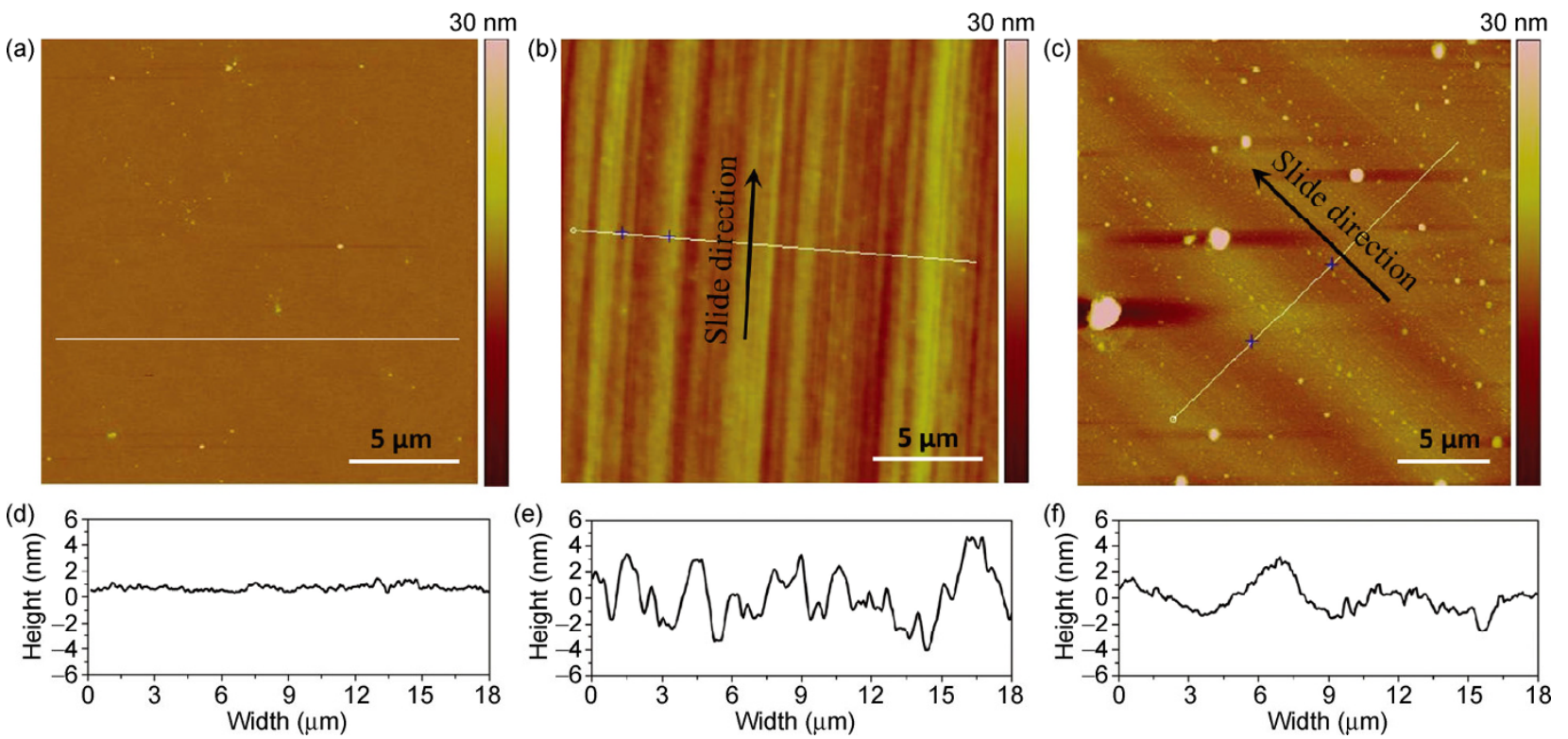

Fig. 5 (a) AFM image of the original surface of the sapphire. (b) AFM image of the track on the surface of the sapphire. (c) AFM image of the worn region on the ruby ball. (d) Cross-sectional profile (white line in (a)) of the original surface of the sapphire. (e) Cross-sectional profile (white line in (b)) of the track on the surface of the sapphire. (f) Cross-sectional profile (white line in (c)) of the worn region on the ruby ball. 


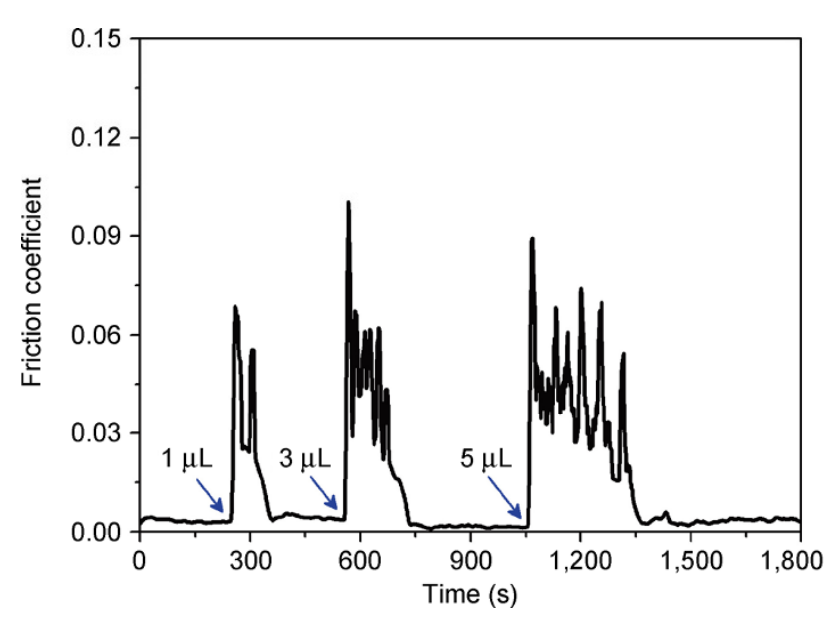

Fig. 6 Friction coefficient with the $\mathrm{H}_{3} \mathrm{PO}_{4}$ solution $(\mathrm{pH}=1.5)$ lubrication after adding different volumes of deionized water $(1 \mu \mathrm{L}$, $3 \mu \mathrm{L}$, and $5 \mu \mathrm{L}$ ) to the track, with a load of $3 \mathrm{~N}$, a rotation speed of $180 \mathrm{rpm}$, and humidity at $30 \%$.

addition, the running-in period becomes longer as the volume of deionized water increases (106 s for $1 \mu \mathrm{L}$, $173 \mathrm{~s}$ for $3 \mu \mathrm{L}$, and $312 \mathrm{~s}$ for $5 \mu \mathrm{L}$ ). This is because excess deionized water requires a longer evaporation period from the contact region as the volume of water becomes larger. Once the excess deionized water has evaporated completely (the mass of the remaining solution on the plate remains constant), the hydrogen bond network can be restored and superlubricity can again be achieved. Therefore, we conclude that superlubricity is closely related to the hydrogen bond network adsorbed on the two friction surfaces.

According to this phenomenon, we can infer that humidity probably does affect superlubricity, because high humidity indicates the presence of water vapor in the air, which can then interfere with the hydrogen bond network and destroy the equilibrium state between the existing $\mathrm{H}_{3} \mathrm{PO}_{4}$ and $\mathrm{H}_{2} \mathrm{O}$ molecules. To verify this inference, the humidity of the test environment was changed from $10 \%$ to $100 \%$ when superlubricity appeared. The friction results at different humidities are shown in Fig. 7. We found that when the humidity is less than $70 \%$, changes in humidity had almost no effect on superlubricity (the friction coefficient remains at 0.004$)$. However, when the humidity increased from $70 \%$ to $100 \%$, the friction coefficient increased from 0.004 to 0.018 . When humidity increased to $85 \%$, superlubricity $(\mu<0.01)$ could not be obtained. This is because the water vapor can easily enter the hydrogen

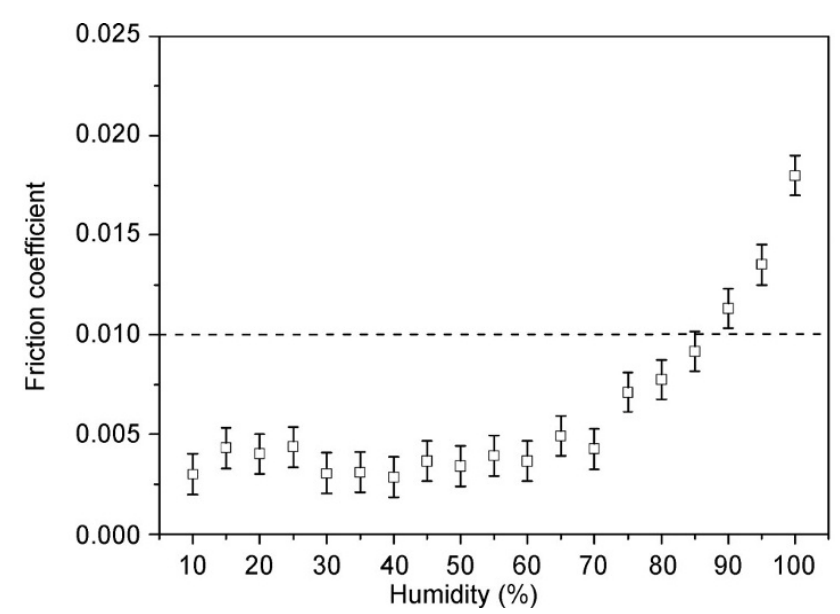

Fig. 7 Relationship between humidity and the friction coefficient with $\mathrm{H}_{3} \mathrm{PO}_{4}$ solution lubrication, at a load of $3 \mathrm{~N}$ and a rotation speed of $180 \mathrm{rpm}$.

bond network when there is a high content of water vapor in the air. Thus we verified that when high humidity occurs, the hydrogen bond network of the $\mathrm{H}_{3} \mathrm{PO}_{4}, \mathrm{H}_{2} \mathrm{PO}_{4}^{-}$, and $\mathrm{H}_{2} \mathrm{O}$ molecules can be destroyed, leading to high friction, in accordance with the phenomenon seen in Fig. 6. However, when the humidity is not high (less than $70 \%$ ), the water vapor in the air cannot easily enter the hydrogen bond network. Neither can the water molecules in the hydrogen bond network easily evaporate from the network, due to the moisture retention tendency of phosphoric acid molecules. Therefore, when humidity is in the range of $10 \%-70 \%$, the equilibrium state between $\mathrm{H}_{3} \mathrm{PO}_{4}$ and $\mathrm{H}_{2} \mathrm{O}$ remains constant, so the friction coefficient also remains constant.

What causes superlubricity? In our previous work, we found two preconditions for superlubricity: first that hydrogen ions be adsorbed on friction surfaces and second that a hydrogen bond network be formed between two surfaces [29, 22]. As for sapphire and ruby, if they are immersed in a strong acid solution $(\mathrm{pH}<4.1)$, hydrogen ions can be adsorbed on their surfaces by a protonation reaction $\left(\mathrm{AlOH}+\mathrm{H}^{+} \rightarrow\right.$ $\mathrm{AlOH}_{2}^{+}, \mathrm{Al}_{2} \mathrm{OH}+\mathrm{H}^{+} \rightarrow \mathrm{Al}_{2} \mathrm{OH}_{2}^{+}$) because there are so many $\mathrm{Al}-\mathrm{OH}$ bonds on the surfaces of sapphire and ruby [30]. Therefore, during the running-in period, the hydrogen ions in the phosphoric acid solution can be adsorbed on the surfaces of sapphire and ruby, which can lead to the two surfaces becoming positively charged. This results in the formation of a stern layer 
and an electrical double layer on the two friction surfaces that reduce the friction force. In addition, a hydrogen bond network among the $\mathrm{H}_{3} \mathrm{PO}_{4}, \mathrm{H}_{2} \mathrm{PO}_{4}^{-}$, and $\mathrm{H}_{2} \mathrm{O}$ molecules also forms on the two friction surfaces (Figs. 3(c) and 3(d)). Therefore, the superlubricity occurring between sapphire and ruby satisfies the two preconditions for superlubricity stated above. We can conclude that the mechanism of superlubricity between sapphire and ruby is attributable to the formation of the hydrogen bond network between the phosphoric acid and water molecules on the stern layer (induced by hydrogen ions) after the running-in period [29].

With regard to the relationship between rotation speed and the friction coefficient, we can infer that the friction pairs are present in the mixed lubrication when superlubricity appears. As shown in Figs. 5(b) and 5(c), the contact surface is not very smooth $\left(R_{\mathrm{z}}=\right.$ $5.506 \mathrm{~nm}$ ) so we can infer the probability of direct asperity contact. We believe there to be three kinds of contact models in the contact region, as shown in Fig. 8. The first is the hydrogen bond network contact, which can be affected by the load and rotation speed due to the hydrodynamic effect between the two sliding surfaces. The second kind is the stern layer contact, which originates from the strong adsorption of hydrogen ions on the friction surface. The third is the direct contact, which occurs when the stern layer is destroyed by high contact pressure. When the sliding speed is high (more than $0.00942 \mathrm{~m} / \mathrm{s}$ ), the hydrogen bond network bears most of the load and plays the primary role in reducing friction. In this case, the

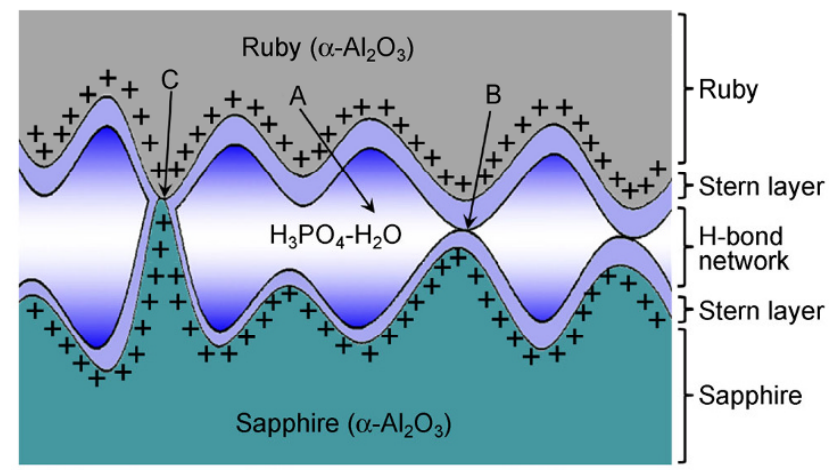

A: H-bond contact, B: Stern layer contact, C: Direct contact

Fig. 8 Schematic illustration of the contact region between the two friction surfaces (ruby and sapphire). relative proportion of stern layer contact is very small so there is almost no direct asperity contact. Because the shearing strength between hydrogen bond networks and the stern layers is very low (forming a hydrated water layer) [31], this leads to ultra-low friction. But when the speed is low (less than $0.00471 \mathrm{~m} / \mathrm{s}$ ), the bearing pressure on the hydrogen bond network reduces due to the reduction in the hydrodynamic effect, which then leads to an increase in the bearing pressure on the stern layer. When the bearing pressure on the stern layer is so high that the stern layer is destroyed, direct asperity contact occurs, which then leads to high friction due to the high shearing strength associated with direct asperity contact. With respect to load, when it is less than $10 \mathrm{~N}$, the hydrogen bond network and the stern layer can bear the load, so there is no direct asperity contact, which can lead to ultra-low friction. But when the load is more than $15 \mathrm{~N}$, the contact pressure is so high that the hydrogen bond network and the stern layer can be destroyed, which leads to direct asperity contact and high friction. Therefore, when the sliding speed is lower than $0.00471 \mathrm{~m} / \mathrm{s}$ and the load becomes higher than $15 \mathrm{~N}$, the proportion of direct asperity contact increases, resulting in an increasing friction coefficient.

Compared to the superlubricity that occurs between $\mathrm{Si}_{3} \mathrm{~N}_{4}$ and glass lubricated by phosphoric acid [21], the maximal contact pressure between sapphire and ruby $(2.57 \mathrm{GPa})$ is much higher than that between $\mathrm{Si}_{3} \mathrm{~N}_{4}$ and glass $(0.7 \mathrm{GPa})$. How is superlubricity achieved using phosphoric acid lubrication under such high pressure? As mentioned in the introduction, high pressure usually leads to significant deformation, severe wear, and the lubricant molecules being squeezed out, all of which impede the formation of superlubricity. The key to achieving superlubricity under high pressure is the excellent surface properties of sapphire and ruby. Both have a high elastic modulus, hardness, and durability under hard wear. When they are in contact with each other, their deformation is very small; the diameter of the contact region is about $67 \mu \mathrm{m}$ under a load of $3 \mathrm{~N}$. According to our white light interferometer images (Figs. 4(a) and 4(b)), the wear is also very minor. The hydrogen bond network adsorbed on the two friction surfaces prevents the phosphoric acid molecules from being easily squeezed 
out even under a high pressure, due to the strong adsorption of hydrogen ions on the surfaces of sapphire and ruby by a protonation reaction. It is thus clear that the excellent surface properties of sapphire and ruby provide favorable conditions for achieving superlubricity under a high pressure. Using friction pairs other than sapphire and ruby that do not have the same surface properties, it is very difficult to obtain superlubricity with phosphoric acid solution lubrication under such high pressure.

\section{Conclusion}

In summary, this study investigated the superlubricity behavior of sapphire against ruby (or sapphire against itself) using phosphoric acid solution lubrication. The resulting ultra-low friction is attributed to the formation of a hydrogen bond network on the stern layer induced by hydrogen ions. We found the superlubricity state to be very stable when the load is in the range of $0.5 \mathrm{~N}$ to $10 \mathrm{~N}$, the sliding speed is in the range of $0.00942 \mathrm{~m} / \mathrm{s}$ to $0.377 \mathrm{~m} / \mathrm{s}$, and the humidity of the test environment is in the range of $10 \%$ to $70 \%$. Moreover, the degree of wear to the sapphire and ruby that occurs during the running-in period is also very small. These excellent friction properties point to the potential application of phosphoric acid solution in the lubrication of sapphire bearing under high pressure, which would not only greatly reduce the consumption of friction energy, but also provide nearly wear-free conditions in the lubrication system.

\section{Acknowledgement}

The work is financially supported by the National Key Basic Research and Development Program (973) of China (2013CB934200), Foundation for the Supervisor of Beijing Excellent Doctoral Dissertation (20111000305), the National Natural Science Foundation of China (NSFC) (Nos. 51321092, 51027007).

Open Access: This article is distributed under the terms of the Creative Commons Attribution License which permits any use, distribution, and reproduction in any medium, provided the original author(s) and source are credited.

\section{Reference}

[1] Hirano M, Shinjo K. Atomistic locking and friction. Phys Rev B 41(17): 11837-11851 (1990)

[2] Erdemir A, Martin J-M. Superlubricity. New York (USA): Elsevier, 2007.

[3] Luo J B, Lu X C, Wen S Z. Developments and unsolved problems in nano-lubrication. Prog Nat Sci 11(3): 173-183 (2001)

[4] Ma Z-Z, Zhang C-H, Luo J-B, Lu X-C, Wen S-Z. Superlubricity of a Mixed Aqueous Solution. Chin Phys Lett 28(5): 056201 (2011)

[5] Hu Y, Ma T, Wang H. Energy dissipation in atomic-scale friction. Friction 1(1): 24-40 (2013)

[6] Li J J, Luo J B. Advancements in superlubricity. Sci China Tech Sci 56(12): 1-11 (2013)

[7] Luo J B, Wen S Z, Li L K Y, Wong P L. Progresses and problems in nano-tribology. Chin Sci Bull 43(5): 369-378 (1998)

[8] Erdemir A. Genesis of superlow friction and wear in diamondlike carbon films. Tribol Int 37(11-12): 1005-1012 (2004)

[9] Martin J M, Donnet C, Lemogne T, Epicier T. Superlubricity of molybdenum-disulfide. Phys Rev B 48(14): 10583-10586 (1993)

[10] Kato K, Umehara N, Adachi K. Friction, wear and $\mathrm{N}_{2}$ lubrication of carbon nitride coatings: A review. Wear 255(11): 1062-1069 (2003)

[11] Raviv U, Laurat P, Klein J. Fluidity of water confined to subnanometre films. Nature 413(6851): 51-54 (2001)

[12] Raviv U, Giasson S, Kampf N, Gohy J F, Jerome R, Klein J. Lubrication by charged polymers. Nature 425(6954): 163-165 (2003)

[13] Briscoe W H, Titmuss S, Tiberg F, Thomas R K, McGillivray D J, Klein J. Boundary lubrication under water. Nature 444(7116): 191-194 (2006)

[14] Klein J. Hydration lubrication. Friction 1(1): 1-23 (2013)

[15] Chen M, Kato K, Adachi K. Friction and wear of self-mated SiC and Si3N4 sliding in water. Wear 250: 246-255 (2001)

[16] Zhou F, Adachi K, Kato K. Sliding friction and wear property of a-C and a- $\mathrm{CN}_{x}$ coatings against $\mathrm{SiC}$ balls in water. Thin Solid Films 514(1-2): 231-239 (2006)

[17] Bouchet M I D B, Matta C, Le-Mogne T, Martin J M, Zhang Q, Goddard W A, III, Kano M, Mabuchi Y, Ye J. Superlubricity mechanism of diamond-like carbon with glycerol. Coupling of experimental and simulation studies. J Phys Conference Series 89: 012003 (2007) 
[18] Matta C, Joly-Pottuz L, Bouchet M I D, Martin J M. Superlubricity and tribochemistry of polyhydric alcohols. Phys Rev B 78(8): 085436 (2008)

[19] Drobek T, Spencer N D. Nanotribology of surface-grafted PEG layers in an aqueous environment. Langmuir 24(4): 1484-1488 (2008)

[20] Li J J, Liu Y H, Luo J B, Liu P X, Zhang C H. Excellent lubricating behavior of brasenia schreberi mucilage. Langmuir 28(20): 7797-7802 (2012)

[21] Li J J, Zhang C H, Luo J B. Superlubricity behavior with phosphoric acid-water network induced by rubbing. Langmuir 27(15): 9413-9417 (2011)

[22] Li J J, Zhang C H, Ma L R, Liu Y H, Luo J B. Superlubricity achieved with mixtures of acids and glycerol. Langmuir 29(1): 271-275 (2013)

[23] Li J J, Zhang C H, Luo J B. Superlubricity achieved with mixtures of polyhydroxy alcohols and acids. Langmuir 29(17): 5239-5245 (2013)

[24] Li J J, Zhang C H, Sun L, Luo J B. Analysis of measurement inaccuracy in superlubricity tests. Tribol Trans 56(1): 141-147 (2013)

[25] Preston C M, Adams W A. Laser Raman-spectroscopic

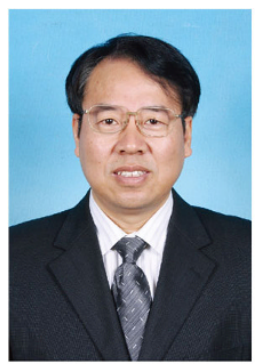

Jianbin LUO. He received his BEng degree from Northeastern University in 1982, and got his MEng degree from Xi'an University of Architecture and Technology in 1988. In 1994, he received his $\mathrm{PhD}$ degree from Tsinghua University and then joined the faculty of Tsinghua University. Prof. Jianbin Luo is an Academician of the Chinese Academy of Sciences and a Yangtze River Scholar

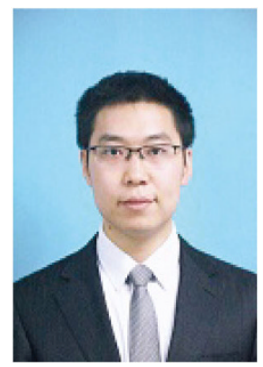

Jinjin LI. He received the BS degree in mechanical engineering from University of Science and Technology of China, Hefei, China, in 2009, and the $\mathrm{PhD}$ degree in mechanical engineering from study of aqueous ortho-phosphate salts. J Phys Chem 83(7): 814-821 (1979)

[26] Adams W A, Preston C M, Chew H A M. High-pressure conductivity and laser Raman-spectroscopic study of aqueous ortho-phosphate solutions at $25^{\circ} \mathrm{C}$. J Chem Phys 70(5): 2074-2080 (1979)

[27] Kameda Y, Sugawara K, Hosaka T, Usuki T, Uemura O. Hydrogen-bonded structure in concentrated aqueous phosphoric acid solutions. Bull Chem Soc Jpn 73(5): 1105-1112 (2000)

[28] Zhou F, Wang X L, Kato K J, Dai Z D. Friction and wear property of a-CN $\mathrm{CN}_{x}$ coatings sliding against $\mathrm{Si}_{3} \mathrm{~N}_{4}$ balls in water. Wear 263: 1253-1258 (2007)

[29] Li J J, Zhang C H, Sun L, Lu X C, Luo J B. Tribochemistry and superlubricity induced by hydrogen ions. Langmuir 28(45): 15816-15823 (2012)

[30] Fitts J P, Shang X M, Flynn G W, Heinz T F, Eisenthal K B. Electrostatic surface charge at aqueous/alpha- $\mathrm{Al}_{2} \mathrm{O}_{3}$ singlecrystal interfaces as probed by optical second-harmonic generation. J Chem Phys 109(16): 7981-7986 (2005)

[31] Raviv U, Klein J. Fluidity of bound hydration layers. Science 297(5586): 1540-1543 (2002)

Distinguished Professor of Tsinghua University, Beijing, China. He was awarded the STLE International Award (2013), the Chinese National Technology Progress Prize (2008), the Chinese National Natural Science Prize (2001), and the Chinese National Invention Prize (1996). Prof. Luo has been engaged in the research of thin film lubrication and tribology in nanomanufacturing. He was invited as a keynote or plenary speaker for 20 times on the international conferences.

Tsinghua University, Beijing, China in 2014. Dr. Li is currently a postdoctoral research fellow at Tsinghua University, Beijing, China. He has published 8 papers indexed by SCI as the first author. His major research areas include superlubricity, wear and lubrication. 